\title{
Association Between Waist Circumference and Carotid Intima-Media Thickness in the General Population
}

\author{
Tatsuya Kamon, ${ }^{1} \mathrm{MD}$, Hidehiro Kaneko, ${ }^{1,2} \mathrm{MD}$, Hidetaka Itoh, ${ }^{1} \mathrm{MD}$, Hiroyuki Kiriyama, ${ }^{1} \mathrm{MD}$, \\ Yoshiko Mizuno, ${ }^{1,3}$ MD, Hiroyuki Morita, ${ }^{1}$ MD, Nobutake Yamamichi, ${ }^{3}$ MD and Issei Komuro, ${ }^{1}$ MD
}

\begin{abstract}
Summary
Waist circumference (WC) is measured for the assessment of abdominal obesity, whereas carotid intimamedia thickness (IMT) is a marker of preclinical atherosclerosis. The relationship between WC and carotid IMT in the general population is not fully understood. In this study, we examined 1,182 subjects (658 men and 524 women, $62.3 \pm 11.7$ years on average) who underwent voluntary health check-ups and sought to determine the optimal cut-off value of WC for predicting carotid IMT thickness. Receiver operating characteristic curve analysis of WC was utilized to predict high carotid IMT (defined as carotid IMT $\geq 1.1 \mathrm{~mm}$ ). We determined that the appropriate WC cut-off value was a WC $\geq 79 \mathrm{~cm}$ for men and women. There was a statistically significant difference in the prevalence of high carotid IMT between WC $\geq 79 \mathrm{~cm}$ and $\mathrm{WC}<79 \mathrm{~cm}$ in both men and women. However, multivariable logistic regression analysis demonstrated that the WC category was independently associated with high carotid IMT in men, but not in women. Our study indicates that the optimal cut-off value of WC to identify preclinical atherosclerosis may be lower than the current Japanese diagnostic criteria for metabolic syndrome (MetS) in both men and women. Compared to women, the association between WC and preclinical atherosclerosis may be more pronounced in men.
\end{abstract}

Key words: Abdominal obesity, Preclinical atherosclerosis, Preventive cardiology

(Int Heart J 2020; 61: 103-108)

$\mathrm{W}$ aist circumference (WC) is measured for the assessment of abdominal obesity. In Japan, the cut-off value of WC for the diagnosis of metabolic syndrome (MetS) is $85 \mathrm{~cm}$ for men, and $90 \mathrm{~cm}$ for women. ${ }^{1,2}$ Abdominal obesity is associated with various metabolic disorders including MetS and the development of subsequent cardiovascular disease (CVD) ${ }^{3.5}$ Voluntary health check-ups are popular among the Japanese people, and the major purpose of voluntary health checkups is the early detection of metabolic disorders and the prevention of future CVD. In voluntary health check-ups, we commonly measure carotid intima-media thickness (IMT) as a marker of preclinical atherosclerosis and a predictor of subsequent CVD.-11)

However, the association between WC and carotid IMT in the general population is not fully understood. In this study, we examined the relationship between WC and carotid IMT as markers of abdominal obesity and preclinical atherosclerosis, respectively. We sought to determine the optimal cut-off value of WC for predicting carotid IMT thickness in our hospital cohort by examining subjects undergoing voluntary health check-ups.

\begin{abstract}
Methods
Study population: We examined 1,243 subjects who underwent medical check-ups at The University of Tokyo Hospital from August 2014 to May 2018. We included subjects aged $\geq 18$ years who were willing to participate in the study; and excluded 2 subjects whose carotid IMT data were unavailable and 59 subjects with a past history of coronary artery disease, stroke, and/or peripheral artery disease. Finally, 1,182 subjects were included in this study. The study subjects were divided into 2 groups based on gender (Patient flowchart is shown in Figure 1). Ethics: This study was performed according to the ethical guidelines of our institution (Approval by the Ethical Committee of The University of Tokyo: 2017-2424). We conducted this study in accordance with the principles of the Declaration of Helsinki. Informed consent was obtained from all individuals enrolled by the opt-out procedure.

Measurement of WC and carotid IMT: WC was measured at the level of the umbilicus with a non-stretchable tape in late expiration while standing. Carotid IMT was measured using a B-mode ultrasound imager (Aplio 300,
\end{abstract}

From the ${ }^{1}$ Department of Cardiovascular Medicine Graduate School of Medicine, The University of Tokyo, Japan, ${ }^{2}$ Department of Advanced Cardiology, Graduate School of Medicine, The University of Tokyo, Japan and ${ }^{3}$ Center for Epidemiology and Preventive Medicine, The University of Tokyo Hospital, Tokyo, Japan.

Address for correspondence: Hidehiro Kaneko, MD, Department of Cardiovascular Medicine, The University of Tokyo Hospital, 7-3-1 Hongo, Bunkyo-ku, Tokyo, 113-8655, Japan. E-mail: kanekohidehiro@gmail.com

Received for publication September 9, 2019. Revised and accepted November 7, 2019.

Released in advance online on J-STAGE January 17, 2020.

doi: 10.1536/ihj.19-470

All rights reserved by the International Heart Journal Association. 


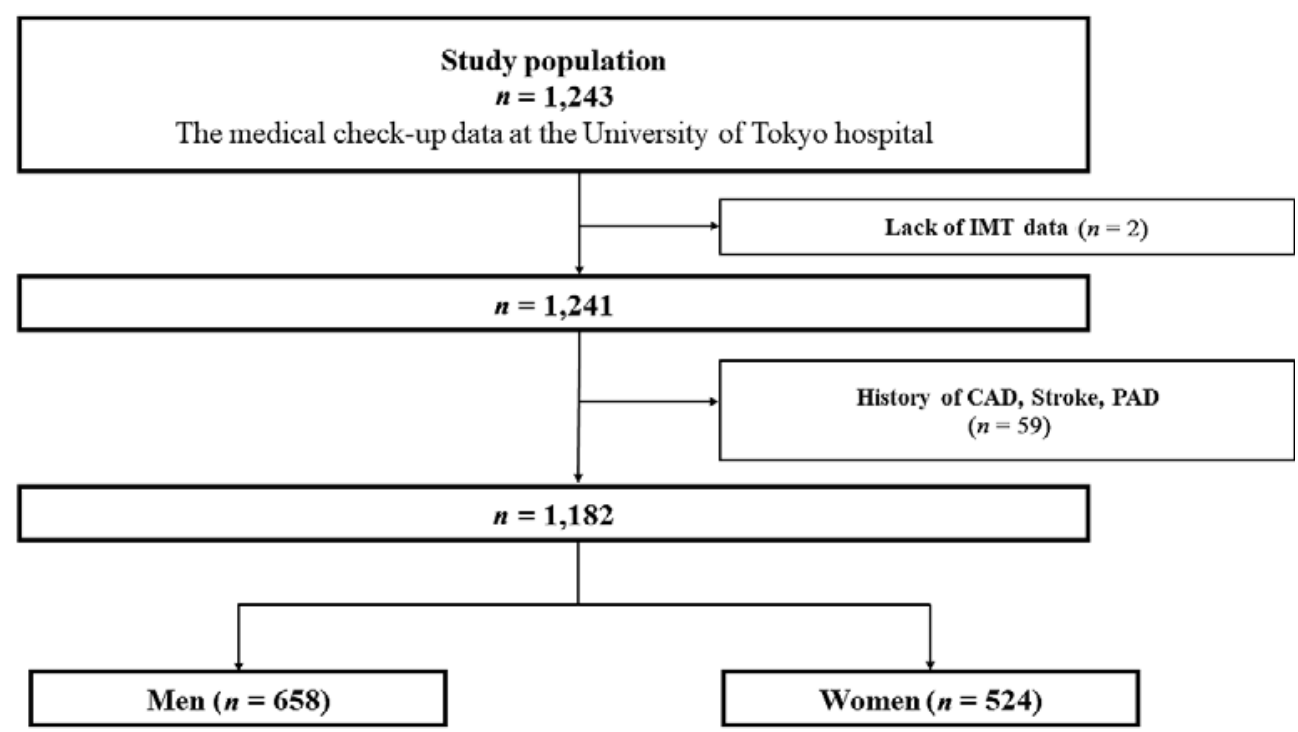

Figure 1. We excluded 2 subjects whose IMT data was unavailable, and 59 subjects with a past history of CAD, stroke, or PAD. We finally included 1,182 subjects in this study. IMT indicates intima-media thickness; CAD, coronary artery disease; and PAD, peripheral artery disease.

Toshiba Corp., Tokyo). Bilateral carotid arteries were examined with a $7.5 \mathrm{MHz}$ probe. The diameter of the internal lumen was calculated using a manual trace along the same length as the IMT, and averaging the distance between the near and far lumen-intima interfaces. The average of the right- and left-side measurements was used to calculate the IMT. We defined high carotid IMT as carotid IMT $\geq 1.1 \mathrm{~mm}$ as previously reported. ${ }^{12,13)}$

Definitions: We collected information regarding the presence of cardiovascular risk factors, including hypertension, diabetes mellitus (DM), and hypercholesterolemia from the medical records of each subject and through selfadministered questionnaires as previously described. ${ }^{14,15}$ ) We defined obesity as having a body mass index (BMI) $\geq$ $25 \mathrm{~kg} / \mathrm{m}^{2}$. Hypertension was defined as a blood pressure $\geq$ $140 / 90 \mathrm{mmHg}$ or current use of antihypertensive medications. DM was defined as a fasting glucose level $\geq 126$ $\mathrm{mg} / \mathrm{dL}$ or current use of oral antidiabetic medications or insulin. Hypercholesterolemia was defined as a total serum cholesterol $>240 \mathrm{mg} / \mathrm{dL}$ or the current use of antihyperlipidemic medications.

Statistical analysis: Categorical and consecutive data of the baseline characteristics are presented as percentages (\%) and the mean \pm standard deviation, respectively. The chi-square test was used to compare the categorical variables. The unpaired t-test was used for the comparison of consecutive variables. Receiver operating characteristic curves were used to demonstrate the $\mathrm{C}$-statistic for prediction of high carotid IMT. Univariate logistic regression analysis was used to assess the association between high WC and high carotid IMT. We performed multivariable logistic regression analysis for the parameters that could affect IMT including age, obesity, hypertension, DM, hypercholesterolemia, smoking, and high WC to determine the independent determinants of high carotid IMT. A probability value of $<0.05$ was considered to indicate sta- tistical significance. We performed all statistical analyses with SPSS (SPSS Inc., Chicago, IL, USA) version 25 software.

\section{Results}

Baseline clinical characteristics: The baseline characteristics of the study subjects are shown in Table I. This study analyzed 1,182 subjects (658 men and 524 women, $62.3 \pm 11.7$ years on average). WC on average was 86.9 $\mathrm{cm}$ for men and $80.0 \mathrm{~cm}$ for women. Overall, carotid IMT was $1.0 \pm 0.3 \mathrm{~mm}$ on average, and high carotid IMT was observed in $36.9 \%$ of study subjects.

Receiver operating characteristic curve for high carotid IMT: Receiver operating characteristic curve analysis of WC to predict high carotid IMT was assessed (Figure 2). The optimal cut-off value was $78.9 \mathrm{~cm}$ in men and $78.85 \mathrm{~cm}$ in women. Therefore, we defined the appropriate $\mathrm{WC}$ cut-off value as $\mathrm{WC} \geq 79 \mathrm{~cm}$ for men and women (Comparison of baseline characteristics between subjects with WC $<79 \mathrm{~cm}$ and WC $\geq 79 \mathrm{~cm}$ was shown in the Supplemental Table).

Association between high WC and high carotid IMT: Chi-square analysis showed a statistically significant difference in the prevalence of high carotid IMT between $\mathrm{WC}<79 \mathrm{~cm}$ and $\mathrm{WC} \geq 79 \mathrm{~cm}$ in both men and women. Similar to the chi-square analysis, univariate logistic regression analysis showed a statistically significant difference in the prevalence of high carotid IMT between $\mathrm{WC}<79 \mathrm{~cm}$ and $\mathrm{WC} \geq 79 \mathrm{~cm}$ in both men and women (Table II). Multivariable logistic regression analysis demonstrated that WC category as well as age and hypertension was independently associated with high carotid IMT in men. However, WC category was not independently associated with high carotid IMT in women (Table III). 
Table I. Baseline Clinical Characteristics

\begin{tabular}{lccrr}
\hline \multicolumn{1}{c}{ Variable } & Overall $(n=1,182)$ & Men $(n=658)$ & Women $(n=524)$ & $P$-value \\
\hline Age $($ years) & $62.3 \pm 11.7$ & $61.3 \pm 11.7$ & $63.5 \pm 11.5$ & 0.002 \\
Body mass index $\left(\mathrm{kg} / \mathrm{m}^{2}\right)$ & $23.5 \pm 3.6$ & $24.5 \pm 3.4$ & $22.2 \pm 3.5$ & $<0.001$ \\
Obesity & $358(30.3 \%)$ & $260(39.5 \%)$ & $98(18.7 \%)$ & $<0.001$ \\
Waist circumference $(\mathrm{cm})$ & $83.8 \pm 10.0$ & $86.9 \pm 9.1$ & $80.0 \pm 9.8$ & $<0.001$ \\
Systolic blood pressure $(\mathrm{mmHg})$ & $120.0 \pm 15.5$ & $121.8 \pm 15.0$ & $117.7 \pm 15.9$ & $<0.001$ \\
Diastolic blood pressure $(\mathrm{mmHg})$ & $75.3 \pm 10.7$ & $76.8 \pm 10.9$ & $73.5 \pm 10.2$ & $<0.001$ \\
Hypertension & $414(35.0 \%)$ & $257(39.1 \%)$ & $157(30.0 \%)$ & 0.001 \\
Diabetes mellitus & $120(10.2 \%)$ & $97(14.7 \%)$ & $23(4.4 \%)$ & $<0.001$ \\
Hypercholesterolemia & $427(36.1 \%)$ & $208(31.6 \%)$ & $219(41.8 \%)$ & $<0.001$ \\
Smokers & $440(37.2 \%)$ & $348(52.9 \%)$ & $92(17.6 \%)$ & $<0.001$ \\
Fasting glucose $(\mathrm{mg} / \mathrm{dL})$ & $99.9 \pm 20.2$ & $103.9 \pm 22.6$ & $94.7 \pm 15.1$ & $<0.001$ \\
HbAlc $(\%)$ & $5.8 \pm 0.6$ & $5.9 \pm 0.7$ & $5.8 \pm 0.5$ & $<0.001$ \\
Total cholesterol $(\mathrm{mg} / \mathrm{dL})$ & $205.9 \pm 34.0$ & $200.2 \pm 33.2$ & $213.1 \pm 33.7$ & $<0.001$ \\
LDL-C (mg/dL) & $124.7 \pm 30.3$ & $123.5 \pm 30.6$ & $126.3 \pm 29.9$ & 0.115 \\
HDL-C (mg/dL) & $65.6 \pm 18.7$ & $59.0 \pm 15.5$ & $73.9 \pm 18.9$ & $<0.001$ \\
TG (mg/dL) & $11.1 \pm 80.6$ & $127.0 \pm 93.3$ & $91.2 \pm 54.9$ & $<0.001$ \\
Carotid IMT (mm) & $1.0 \pm 0.3$ & $1.1 \pm 0.3$ & $1.0 \pm 0.3$ & $<0.001$ \\
Carotid IMT $\geq 1.1 \mathrm{~mm}$ & $436(36.9 \%)$ & $285(43.3 \%)$ & $151(28.8 \%)$ & $<0.001$ \\
\hline
\end{tabular}

Data are expressed as mean \pm standard deviation or number (percentage). HbAlc indicates hemoglobin A1c; LDL-C, low density lipoprotein cholesterol; HDL-C, high density lipoprotein cholesterol; TG, triglycerides; and IMT, intima-media thickness.

A

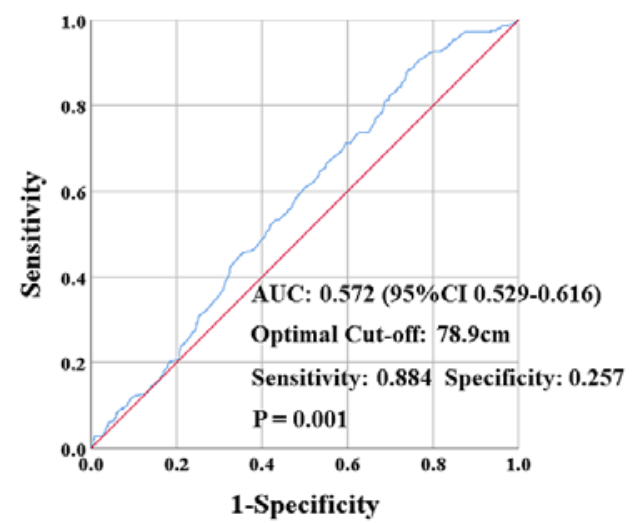

B

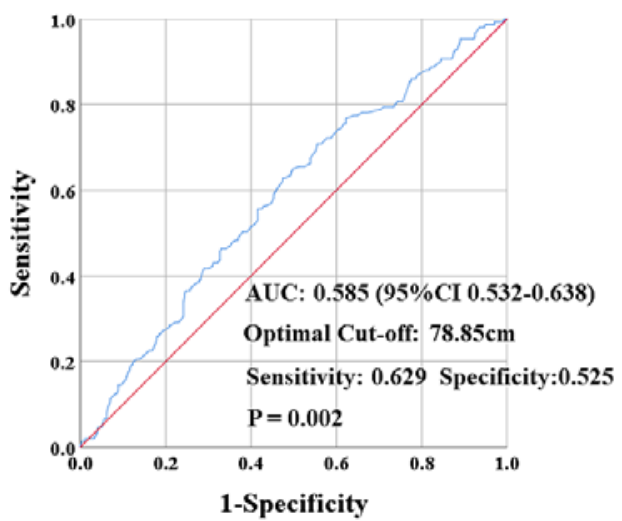

Figure 2. Receiver-operating characteristic curve and AUC showed the ability of WC to predict IMT $\geq 1.1 \mathrm{~mm}$ and optimal cut-off value with the highest combination of sensitivity and specificity. AUC was 0.572 and optimal cut-off value was $78.9 \mathrm{~cm}$ in men, while AUC was 0.585 and optimal cut-off value was $78.85 \mathrm{~cm}$ in women. AUC indicates area under the curve; and CI, confidence interval.

\section{Discussion}

The key finding of this study suggests that the optimal cut-off level of WC for the prediction of high carotid IMT is $79 \mathrm{~cm}$ for both men and women. High carotid IMT was more prevalent in subjects with $\mathrm{WC} \geq 79 \mathrm{~cm}$ than in those with $\mathrm{WC}<79 \mathrm{~cm}$. Multivariable analysis showed that $\mathrm{WC} \geq 79 \mathrm{~cm}$ was independently associated with high carotid IMT in men, but not in women.

Abdominal obesity is a common and established risk factor for metabolic disorders including MetS, and subsequent CVD. ${ }^{16-18)}$ Abdominal obesity is spreading rapidly owing to an industrialized and westernized lifestyle, and almost $50 \%$ of men and $20 \%$ of women were diagnosed with abdominal obesity in Japan. ${ }^{19)}$ Therefore, the early detection and intervention of abdominal obesity is essen- tial to prevent future CVD. WC is considered an excellent parameter for the diagnosis of abdominal obesity, ${ }^{20,21)}$ and WC is used routinely in health check-ups for the general population to detect metabolic disorders at an early stage.

Carotid IMT is a well-known marker of subclinical atherosclerosis in the general population, and previous studies have shown that high carotid IMT is a good predictor for CVD. Oei, et al showed that there was a clear association between coronary calcification assessed by electron beam CT and carotid IMT thickness in a middle aged population. ${ }^{22}$ Bots, et al reported that carotid IMT thickness was significantly associated with the occurrence of stroke and myocardial infarction in a community-based cohort. $^{23)}$

The Japanese Society of Internal Medicine proposes that a WC cut-off value of $85 \mathrm{~cm}$ for men and $90 \mathrm{~cm}$ for 
Table II. Waist Circumference and High Carotid IMT

\begin{tabular}{lcccccc}
\hline \multicolumn{1}{c}{ Variable } & \multicolumn{3}{c}{ Men } & \multicolumn{3}{c}{ Women } \\
& OR & $95 \% \mathrm{CI}$ & $P$-value & OR & $95 \%$ CI & $P$-value \\
\hline $\begin{array}{l}\text { Waist circumference } \\
<79 \mathrm{~cm}\end{array}$ & \multicolumn{3}{c}{ (reference) } & & (reference) & \\
$\geq 79 \mathrm{~cm}$ & 2.6 & $1.7-4.1$ & $<0.001$ & 1.8 & $1.2-2.7$ & 0.002 \\
\hline
\end{tabular}

IMT indicates intima-media thickness; OR, odds ratio; and CI, confidence interval.

Table III. Determinants of High Carotid IMT

\begin{tabular}{|c|c|c|c|c|c|c|}
\hline \multirow{2}{*}{ Variable } & \multicolumn{3}{|c|}{ Men } & \multicolumn{3}{|c|}{ Women } \\
\hline & OR & $95 \% \mathrm{CI}$ & $P$-value & OR & $95 \% \mathrm{CI}$ & $P$-value \\
\hline Age & 1.1 & $1.1-1.1$ & $<0.001$ & 1.1 & $1.0-1.1$ & $<0.001$ \\
\hline Obesity & 1.4 & $0.9-2.0$ & 0.128 & 1.1 & $0.6-1.9$ & 0.821 \\
\hline Hypertension & 1.5 & $1.0-2.2$ & 0.031 & 2.0 & $1.3-3.1$ & 0.002 \\
\hline Diabetes mellitus & 1.3 & $0.8-2.1$ & 0.358 & 3.3 & $1.2-9.0$ & 0.017 \\
\hline Hypercholesterolemia & 1.1 & $0.7-1.6$ & 0.662 & 1.2 & $0.8-1.8$ & 0.397 \\
\hline Smoking & 1.0 & $0.7-1.4$ & 0.926 & 0.6 & $0.3-1.1$ & 0.107 \\
\hline \multicolumn{7}{|l|}{ Waist circumference } \\
\hline$<79 \mathrm{~cm}$ & \multicolumn{3}{|c|}{ (reference) } & \multicolumn{3}{|c|}{ (reference) } \\
\hline$\geq 79 \mathrm{~cm}$ & 2.4 & $1.4-4.0$ & 0.001 & 1.3 & $0.8-2.0$ & 0.353 \\
\hline
\end{tabular}

IMT indicates intima-media thickness; OR, odds ratio; and CI, confidence interval.

women is a suitable predictor of MetS risk. ${ }^{1)}$ Previous studies showed this WC cut-off value was associated with a visceral fat area $\geq 100 \mathrm{~cm}^{2}$ and the associated CVD risks. ${ }^{21)}$ However, the optimal WC cut-off of diagnosis for MetS is still controversial. ${ }^{24-26)}$

In this study, we examined subjects who underwent voluntary health check-ups, this cohort was predicted to reflect the general population. Based on a receiver operating characteristic curve analysis, we determined the appropriate WC cut-off value for prediction of high carotid IMT as $\geq 79 \mathrm{~cm}$ for both men and women. Therefore, the optimal cut-off of WC for the detection of preclinical atherosclerosis in the general population may be different from the current Japanese diagnostic criteria of MetS (85 $\mathrm{cm}$ for men, $90 \mathrm{~cm}$ for women). The sensitivity and specificity of the current Japanese diagnostic criteria of WC for detecting IMT $\geq 1.1 \mathrm{~mm}$ is $62 \%$ and $48 \%$ for men, and $19 \%$ and $88 \%$ for women, respectively. On the other hand, the sensitivity and specificity of $\mathrm{WC} \geq 79 \mathrm{~cm}$ is $88 \%$ and $26 \%$ for men, and $63 \%$ and $53 \%$ for women, respectively. Needless to say, lowering the cut-off value of WC (79 cm for both men and women) increased the sensitivity, but decreased the specificity. Particularly, the change in the sensitivity and the specificity among women are remarkable. Given that the purpose of health checkups is the primary prevention and sensitivity is important, we believe that the cut-off value which we suggested in this study is worth considering.

Multivariable analysis indicated that high WC was independently associated with high carotid IMT as well as age and hypertension in men, suggesting that the measurement of WC is informative for the assessment of abdominal obesity, and the risk of preclinical atherosclerosis in men. However, high WC was not independently associated with high carotid IMT in women. Multivariable analysis showed that age, hypertension, and DM were independently associated with high carotid IMT in women. The predictive value of these risk factors may overwhelm the impact of high WC in women. Various preceding studies examined the possible gender difference in the association between metabolic risk factors and IMT. ${ }^{27-32)}$ This point is still under debate and is clinically important for the risk assessment of the general population from the perspective of preventive cardiology. Further study is required to clarify the significance of WC for the prediction of preclinical atherosclerosis in women.

Today, the importance of preventive cardiology, particularly primary prevention, has been strongly recognized. Accordingly, the Japanese Ministry of Health, Labour and Welfare launched its Specific Health Checkups and Specific Health Guidance (annual health screening and health promotion services) in 2008. The aim of Specific Health Checkups is the early detection and intervention for citizens with or at a high risk for lifestyle-related diseases, particularly MetS, and prevention of future CVD. In the Specific Health Checkups, high WC is measured for the assessment of abdominal obesity, and it is a mandatory condition for the diagnosis of MetS $(85 \mathrm{~cm}$ for men, $90 \mathrm{~cm}$ for women). ${ }^{1)}$ Therefore, the cut-off value of $\mathrm{WC}$ is important for the diagnosis of MetS and the primary prevention of CVD in Japan. Our study indicates that the cut-off value of WC should be lower than that of the current Japanese diagnostic criteria for detecting preclinical atherosclerosis using carotid IMT.

This study has several limitations. First, it is based on a single-center cohort, therefore, the results cannot be easily generalized. The sample size is limited, thus the statistical power might not be sufficient for any nonsignificant data to be conclusive. Second, we could not examine a cause-effect relationship because of the nature of the cross-sectional design. Although we performed multivariable analysis, we could not exclude the possibility of unmeasured confounders. Third, we did not know the menopausal status of the female subjects, therefore, 
we could not investigate the impact of menopause on the development of atherosclerosis.

\section{Conclusions}

The optimal cut-off value of WC to identify preclinical atherosclerosis (defined as carotid IMT $\geq 1.1 \mathrm{~mm}$ ) may be lower than the current Japanese diagnostic criteria for MetS in both men and women. Compared to women, the association between WC and preclinical atherosclerosis might be more pronounced in men. Further studies are needed to determine the optimal cut-off value of WC for abdominal obesity in the general population, particularly for the early detection of preclinical atherosclerosis.

\section{Acknowledgments}

We thank the staff of the Center for Epidemiology and Preventive Medicine of our institute for their valuable assistance.

\section{Disclosure}

Conflicts of interest: Research funding and scholarship funds (Hidehiro Kaneko) from Medtronic Japan CO., LTD, Abbott Medical Japan CO., LTD, Boston Scientific Japan CO., LTD, and Fukuda Denshi, Central Tokyo CO., LTD. There are no other conflicts of interest.

\section{References}

1. Committee to evaluate diagnostic standards for metabolic syndrome. Definition and the diagnostic standard for metabolic syndrome. Nihon Naika Gakkai Zasshi 2005; 94: 794-809 (Japanese)

2. Itoh $\mathrm{H}$, Kaneko $\mathrm{H}$, Kiriyama $\mathrm{H}$, et al. Effect of metabolically healthy obesity on the development of carotid plaque in the general population: A community-based cohort study. J Atheroscler Thromb 2019 (in press).

3. Carr DB, Utzschneider KM, Hull RL, et al. Intra-abdominal fat is a major determinant of the National Cholesterol Education Program Adult Treatment Panel III criteria for the metabolic syndrome. Diabetes 2004; 53: 2087-94.

4. Despres JP, Moorjani S, Lupien PJ, Tremblay A, Nadeau A, Bouchard C. Regional distribution of body fat, plasma lipoproteins, and Cardiovascular disease. Arteriosclerosis 1990; 10: 497-511.

5. Zhang C, Rexrode KM, van Dam RM, Li TY, Hu FB. Abdominal obesity and the risk of all-cause, cardiovascular, and cancer mortality: sixteen years of follow-up in US women. Circulation 2008; 117: 1658-67

6. de Groot E, Hovingh GK, Wiegman A, et al. Measurement of arterial wall thickness as a surrogate marker for atherosclerosis. Circulation 2004; 109: III33-8.

7. Kitamura A, Iso H, Imano $\mathrm{H}$, et al. Carotid intima-media thickness and plaque characteristics as a risk factor for stroke in Japanese elderly men. Stroke 2004; 35: 2788-94.

8. Rosvall M, Janzon L, Berglund G, Engstrom G, Hedblad B. Incidence of stroke is related to carotid IMT even in the absence of plaque. Atherosclerosis 2005; 179: 325-31.

9. Rosvall M, Janzon L, Berglund G, Engstrom G, Hedblad B. Incident coronary events and case fatality in relation to common carotid intima-media thickness. J Intern Med 2005; 257: 430-7.

10. Bots ML, Baldassarre D, Simon A, et al. Carotid intima-media thickness and coronary atherosclerosis: weak or strong relations? Eur Heart J 2007; 28: 398-406.

11. O'Leary DH, Polak JF, Kronmal RA, et al. Carotid-artery intima and media thickness as a risk factor for myocardial infarction and stroke in older adults. N Engl J Med 1999; 340: 14-22.

12. Salonen R, Salonen JT. Progression of carotid atherosclerosis and its determinants: a population-based ultrasonography study. Atherosclerosis 1990; 81: 33-40.

13. Itoh H, Kaneko H, Kiriyama H, et al. Relation between the Updated Blood Pressure Classification according to the American College of Cardiology/American Heart Association Guidelines and Carotid Intima-Media Thickness. Am J Cardiol 2019; 124: 396-401.

14. Itoh H, Kaneko H, Kiriyama $\mathrm{H}$, et al. Effect of Body Weight Change on blood pressure in Japanese general population with body mass index $\geq 22 \mathrm{~kg} / \mathrm{m}^{2}$ : A community-based cohort study. Int Heart J 2019; 60: 1381-6.

15. Itoh H, Kaneko H, Kiriyama $\mathrm{H}$, et al. Association between changes in body weight and fat weight in middle age general population: A community-based cohort study. Int Heart J 2020 (in press).

16. Cerhan JR, Moore SC, Jacobs EJ, et al. A pooled analysis of waist circumference and mortality in 650,000 adults. Mayo Clin Proc 2014; 89: 335-45.

17. Yusuf S, Hawken S, Ounpuu S, et al. Obesity and the risk of myocardial infarction in 27,000 participants from 52 countries: a case-control study. Lancet 2005; 366: 1640-9.

18. Coutinho T, Goel K, Correa de Sa D, et al. Combining body mass index with measures of central obesity in the assessment of mortality in subjects with coronary disease: role of "normal weight central obesity". J Am Coll Cardiol 2013; 61: 553-60.

19. Ministry of health, labour and Welfare homepage [internet]. Available at: https://www.mhlw.go.jp/bunya/kenkou/eiyou06/pdf/ 01-kekka.pdf. Accessed August 16, 2019.

20. The Examination Committee of Criteria for 'Obesity Disease' in Japan, Japan Society for the Study of Obesity. New criteria for 'obesity disease' in Japan. Circ J 2002; 66: 987-92.

21. Hiuge-Shimizu A, Kishida K, Funahashi T, et al. Absolute value of visceral fat area measured on computed tomography scans and obesity-related cardiovascular risk factors in large-scale Japanese general population (the VACATION-J study). Ann Med 2012; 44: 82-92.

22. Oei HHS, Vliegenthart R, Hak AE, et al. The association between coronary calcification assessed by electron beam computed tomography and measures of extracoronary atherosclerosis: The Rotterdam Coronary Calcification Study. J Am Coll Cardiol 2002; 39: 1745-51.

23. Bots ML, Hoes AW, Koudstaal PJ, Hofman A, Grobbee DE. Common carotid intima-media thickness and risk of stroke and myocardial infarction: the Rotterdam Study. Circulation 1997; 96: 1432-7.

24. Doi Y, Ninomiya T, Hata J, et al. Proposed criteria for metabolic syndrome in Japanese based on prospective evidence: The Hisayama Study. Stroke 2009; 40: 1187-94.

25. Oka R, Kobayashi J, Yagi K, et al. Reassessment of the cutoff values of waist circumeference and visceral fat area for identifying Japanese subjects at risk for the metabolic syndrome. Diabetes Res Clin Pract 2008; 79: 474-81.

26. Hayashi T, Leonetti DL, Boyko EJ, Kahn SE, Mcneely MJ, Fujimoto WY. Minimum waist and visceral fat values for identifying Japanese Americans at risk for the metabolic syndrome. Diabetes Care 2007; 30: 120-7.

27. Kawamoto R, Tomita H, Inoue A, Ohtsuka N, Kamitani A. Metabolic syndrome may be a risk factor for early carotid atherosclerosis in women but not in men. J Atheroscler Thromb 2007; 14: 36-43.

28. Cuspidi C, Sala C, Provenzano F, et al. Metabolic syndrome and subclinical carotid damage: a meta-analysis from populationbased studies. J Hypertens 2018; 36: 23-30.

29. Takayama S, Kawamoto R, Kusunoki T, Abe M, Onji M. Uric 
acid is an independent risk factor for carotid atherosclerosis in a Japanese elderly population without metabolic syndrome. Cardiovasc Diabetol 2012; 11: 2.

30. Tian X, Xiong H, Wu D, Zhang R, Lu M, Zhang YT. Age and sex-specific relationships between blood pressure variability and carotid intima-media thickness. Australas Phys Eng Sci Med 2016; 39: 967-76.

31. Łoboz-Rudnicka M, Jaroch J, Bociąga Z, et al. Impact of cardiovascular risk factors on carotid intima-media thickness: sex differences. Clin Interv Aging 2016; 11: 721-31.
32. Sinning C, Wild PS, Echevarria FMO, et al. Sex Differences in Early Carotid Atherosclerosis (from the Community-Based Gutenberg-Heart Study). Am J Cardiol 2011; 107: 1841-7.

\section{Supplemental Files}

Supplemental Table

Please see supplemental files; https://doi.org/10.1536/ihj.19-470 